\title{
Produção de interleucina-10 na gestação reduz a taxa de replicação do HIV-1 em culturas de linfócitos maternos
}

\author{
Interleukin-10 production during pregnancy reduces HIV-1 replicaction in cultures of maternal \\ lymphocytes
}

Bruno Monção Paolino ${ }^{1}$, Odalis Karen Vasquez Araoz ${ }^{1}$, Ana Cristina Marques Wing ${ }^{1}$, Ana Luíza Furtado da Silva ${ }^{1}$, Regina Rocco ${ }^{2}$, Catharina Lauria ${ }^{3}$, Rodrigo Brindeiro ${ }^{4}$, Cleonice Alves de Melo Bento ${ }^{5}$

\section{RESUMO}

Objetivo: avaliar a proliferação de células T e a produção de citocinas em gestantes infectadas pelo HIV-1 e seu impacto na replicação viral in vitro. Métodos: sangue periférico de 12 gestantes infectadas pelo HIV-1 e de seus neonatos, bem como de 10 gestantes HIV-1 negativas, foi colhido e a quantidade de linfócitos TCD4 ${ }^{+}$e TCD8 ${ }^{+}$periféricos foi avaliada por citometria de fluxo. Para obter plasma ou células mononucleares periféricas (PBMC), as amostras foram centrifugadas na ausência ou presença de um gradiente de Ficoll-Hypaque, respectivamente. As PBMC foram mantidas em cultura por sete dias na presença de fito-hemaglutinina mais IL-2 recombinante e a resposta linfoproliferativa de células T foi analisada pelo método de exclusão em azul de Trypan. Em alguns experimentos, as culturas foram mantidas na presença adicional de anticorpo anti-IL-10. Os plasmas e sobrenadantes das culturas de PBMC ativadas foram submetidos à análise da produção de citocinas, pelo método ELISA indireto, e a carga viral, detectada pelo RT-PCR. Resultados: independente da carga viral plasmática, a resposta linfoproliferativa em culturas de células obtidas de gestantes infectadas pelo HIV foi inferior às amostras normais $\left[4,2 \pm 0,37 v s 2,4 \pm 0,56\left(x 10^{6}\right)\right.$ células $\left./ \mathrm{mL} ; \mathrm{p}<0.005\right]$. Tanto em gestantes normais quanto em pacientes com cargas virais baixas, os níveis de IL-10 foram mais elevados que os das gestantes com elevada replicação viral $(9.790 \pm 3.224$ vs $1.256 \pm 350 \mathrm{pg} / \mathrm{mL} ; \mathrm{p}=0.002)$. Níveis elevados de TNF- $\alpha$ no $\operatorname{soro}(7.200 \pm 2.440$ vs $510 \pm 476$ $\mathrm{pg} / \mathrm{mL})$ e nas culturas de células $(21.350 \pm 15.230$ vs $1.256 \pm 350 \mathrm{pg} / \mathrm{mL})$ correlacionaram-se à carga viral plasmática elevada e a infecção neonatal. O bloqueio da IL-10 endógena com anticorpos anti-IL-10 aumentou a replicação do HIV-1 em cultura de células. Conclusão: nossos resultados sugerem que a IL-10 exerce influência negativa na replicação viral, o que provavelmente contribui para reduzir o risco de infecção vertical.

PALAVRAS-CHAVE: Síndrome da imunodeficiência adquirida; Citocinas; HIV-1; Células Th1; Linfócitos t

\section{ABSTRACT}

Purpose: to evaluate T cell proliferation and cytokine production in HIV-1-infected pregnant women and their impact on in vitro virus replication. Methods: peripheral blood from $12 \mathrm{HIV}-1$-infected pregnant women and from their neonates was collected. As control, 10 samples from non-infected pregnants were also colleted. The $\mathrm{CD}^{+}$and $\mathrm{CD}^{+} \mathrm{T}$ cell counts were assayed by flow cytometry. Peripheral blood mononuclear cells (PBMC) and plasma were obtained by centrifugation with and without FicollHypaque gradient, respectively. The freshly purified PBMC were kept in cultures for seven days with PHA plus r-IL-2, and the lymphoproliferative response was assayed by Trypan blue dye exclusion. In some experiments we added anti-IL-10 monoclonal antibody. The plasma samples and supernatants from cell cultures were stored to determine both peripheral cytokine levels, by ELISA sandwich, and viral load, by RT-PCR. Results: the results showed that the lymphoproliferative response was smaller in cultures obtained from HIV-1-infected women than in control cultures [4.2 $\pm 0.37 \mathrm{vs} 2.4 \pm 0.56$ (x $10^{6}$ cell $/ \mathrm{mL}$ ), $\left.\mathrm{p}<0.005\right]$. In both control and infected pregnant women who had low plasma viral load, the level of IL-10 was higher than in those with high viral replication $(9.790 \pm 3.224$ vs $1.256 \pm 350 \mathrm{pg} / \mathrm{mL}, \mathrm{p}=0.002)$. The elevated TNF- $\alpha$ production detected in serum $(7.200 \pm 2.440 \mathrm{pg} / \mathrm{mL})$ and supernatants $(21.350 \pm 15.230 \mathrm{pg} / \mathrm{mL})$ was associated with higher plasma viral loads and vertical infection. The IL-10 blockade by anti-IL-10 antibodies augmented viral replication in the cell cultures. Conclusion: these results indicate that IL-10 production exerts a negative influence on virus replication, diminishing the probability of intrauterine HIV-1 infection.

KEYWORDS: Aqured immunodeficency; Cytokines; HIV-1; Th1-cells; t Lymphocytes

\footnotetext{
Trabalho realizado no Hospital Universitário Graffrée Guinle (HUGG/UNIRIO)

1 Graduando em Medicina da Faculdade de Medicina da Universidade Federal do Estado do Rio de Janeiro (UNIRIO).

2 Obstetra do Hospital Universitário Gaffrée Guinle, Universidade do Rio de Janeiro - UNIRIO - Rio de Janeiro (RJ) - Brasil.

3 Biomédica do Hospital Universitário Pedro Ernesto/Universidade Estadual do Rio de Janeiro - UERJ - Rio de Janeiro (RJ) - Brasil.

4 Professor Adjunto, Departamento de Genética / Universidade Federal do Rio de Janeiro - UFRJ - Rio de Janeiro (RJ) - Brasil.

5 Professora Adjunta, Departamento de Microbiologia e Parasitologia, Universidade do Rio de Janeiro - UNIRIO - Rio de Janeiro (RJ) - Brasil. Correspondência: Cleonice Alves de Melo Bento

Rua Barão do Flamengo, 28/904 - Flamengo - 22220-080 - Rio de Janeiro - RJ - Telefones: (21) 2224-4505/2558-7586/9409-4048 - Fax: (21) 22325332/2225-3812 - e-mail: cbento@unirio.br

Recebido em: 125/5/2005 Aceito com modificações em: 12/7/2005
} 


\section{Introdução}

A gestação é condição fisiológica com mudanças imunológicas e endócrinas envolvidas na aceitação do feto $^{1,2}$. Fortes evidências apontam para uma rede de citocinas produzidas por clones de células T maternas como sendo elemento central na imunomodulação $0^{2-4}$. Por produzirem grandes quantidades de citocinas que regulam uma variedade de funções, os linfócitos T executam um papel capital na resposta imune. Nesse contexto, durante a resposta imune, os linfócitos T $\mathrm{CD}^{+}$ virgens podem se diferenciar nos fenótipos Th1, Th2, Tr-1 ou Tr-3, que secretam padrões distintos de citocinas e, portanto, medeiam diferentes funções ${ }^{5}$. Vários fatores influenciam a diferenciação final desses linfócitos $\mathrm{T}$ ativados, mas citocinas e hormônios parecem ser decisivos no destino do fenótipo diferenciado ${ }^{1,5-7}$. Com relação à gestação, dois pólos têm sido o foco dos estudos na imunorregualação materna: os linfócitos Th1 e as células reguladoras Tr-1 e Tr-3. Enquanto dados na literatura apontam que a indução de resposta imune materna do tipo Th1 é deletéria ao desenvolvimento fetal, vários estudos sugerem que citocinas produzidas pelas células $\mathrm{T}$ reguladoras 1 e 3 são protetoras ${ }^{3,4,6-9}$.

Durante a gestação, o sistema imune materno é desafiado com moléculas de HLA paternas associadas a células fetais que atingem o seu sangue periférico ${ }^{1,5,8-10}$. A sensibilização materna contra tais antígenos é orientada pelos linfócitos Th1, que secretam grandes quantidades de interleucina-2 (IL-2) e IFN- $\gamma$, que auxiliam na ativação dos linfócitos $\mathrm{T} \mathrm{CD}^{+}$dirigidos contra células fetais que expressam moléculas de HLA paternas. Estas células $\mathrm{T}^{\mathrm{CD}} 8^{+}$sensibilizadas, conhecidas como linfócitos $\mathrm{T}$ citotóxicos, além de danificarem diretamente os anexos fetais, amplificam a resposta local por perpertuar a secreção de citocinas próinflamatórias, tais como interferon- $\gamma$ (IFN- $\gamma$ ) e fator de necrose tumoral (TNF- $\alpha$ ). Estas citocinas, por aumentarem o poder microbicida dos macrófagos e das células NK uterinas ${ }^{4,7-10}$, estão envolvidas em infartos placentários e descolamento prematuro da placenta, determinantes de sofrimento fetal e elevado risco de óbito perinatal ${ }^{8,9}$. Entretanto, para evitar a produção de citocinas embriotóxicas, a mãe deve passar, por um tempo determinado, por mudanças fisiológicas necessárias para dar suporte à gestação. Neste sentido, o cortisol, o estrogênio e, principalmente, a progesterona são responsáveis pela geração de uma rede de citocinas antiinflamatórias, tais como a IL-10 e o fator $\beta$ de crescimento transformante
(TGF- $\beta$ ), que dará suporte ao desenvolvimento fetal na cavidade uterina ${ }^{1,2,6,7,10-14}$.

A progesterona e o estrogênio, além de atuarem no trofoblasto fazendo-o secretar a IL-10 e o TGF- $\beta^{1,6,13}$, estão também envolvidos na tolerância a antígenos fetais, por induzirem linfócitos $\mathrm{T}$ deciduais e periféricos a se diferenciarem em células $\mathrm{T}$ reguladores do tipo 1 e $3^{3,4,6,13}$. As células de fenótipo T regulador dos tipos 1 e 3 (Tr-1 e Tr-2) secretam grandes quantidades de IL-10 e TGF- $\beta$, respectivamente. A presença dessas citocinas antagoniza a função das células Th1 por bloquear a produção de TNF- $\alpha$ e INF- $\gamma^{5,13,15}$.

A freqüência de infecção pelo HIV em mulheres adultas vem aumentando consideravelmente nos últimos tempos, fato esse que tem importância fundamental na transmissão vertical do virus. A gravidez não afeta o curso da infecção pelo HIV-1 ${ }^{16}$, mas o impacto dessa infecção sobre a rede de citocinas e na manutenção da gestação tem sido pouco investigado. Sabe-se, por exemplo, que em adultos a infecção crônica pelo HIV-1 está relacionada à ativação do sistema imune com produção elevada de citocinas pró-inflamatórias ${ }^{17}$. Algumas delas, como o TNF- $\alpha$ e o IFN- $\gamma$, favorecem a replicação viral em linfócitos $\mathrm{T}^{\mathrm{CD}} 4^{+}$hu$\operatorname{manos}^{18}$. A produção sustentada dessas citocinas é garantida não apenas pela resposta mediada pelos linfócitos $\mathrm{T} \mathrm{CD}^{+}$contra antígenos do vírus, como também por uma ativação inespecífica do sistema imunológico induzida por vários produtos do HIV-1 $1^{17,18}$. Ademais, eventos não relacionados à infecção viral, como co-infecções recorrentes ou imunizações, elevam transitoriamente a viremia plasmática por elevar o grau de ativação imune ${ }^{19-}$ ${ }^{21}$. O perfil de citocinas em gestantes infectadas pelo HIV deve, portanto, desequilibrar a rede estabelecida no processo natural da gestação em favor das citocinas inflamatórias, o que pode ter implicações deletérias ao desenvolvimento fetal. Neste contexto, a introdução de novas drogas antiretrovirais (ARVs) no manejo da infecção pelo HIV tem reduzido os distúrbios imunológicos por controlar a replicação viral. Pelo protocolo adotado pelo Ministério da Saúde, mulheres grávidas infectadas pelo HIV-1 devem iniciar o tratamento a partir da $14^{a}$ semana de gestação e mantê-lo até o final da mesma. Apesar de os regimes ARVs atualmente disponiveis não erradicarem o HIV-1, seu uso na gravidez trouxe grande impacto na redução dos riscos de transmissão vertical ${ }^{16}$.

O objetivo desse trabalho foi avaliar a influência da infecção pelo HIV-1 em alguns eventos imunológicos maternos, como a linfoproliferação e a produção de citocinas definidoras de diferentes fenótipos de resposta imunológica, e o impacto dessa relação na dinâmica da replicação viral. 


\section{Métodos}

Foi realizado estudo transversal com gestantes infectadas pelo HIV-1 $(\mathrm{n}=12)$ com idade entre 21 e 37 anos, acompanhadas no serviço de Obstetrícia do Hospital Universitário Graffrée Guinle (HUGG/UNIRIO). Neste estudo, visamos avaliar o impacto da infecção viral na imunomodulação materna. Para não haver interferência na análise dos dados, gestantes que apresentassem comorbidades, como outras doenças sexualmente transmissiveis, foram excluídas. Após aprovação pelo Comitê de Ética do HUGG, as amostras de sangue periférico das mães e do cordão umbilical de seus filhos foram colhidas após cada gestante ter lido e assinado o termo de consentimento livre e esclarecido. Como controle, amostras do sangue periférico de 10 gestantes HIV-1 negativas saudáveis, com idade e tempo gestacional compatíveis, foram utilizadas.

\section{Amostras clinicas e obtenção de células mononucleares do sangue periférico}

Vinte $\mathrm{mL}$ de sangue periférico materno e do cordão umbilical foram colhidos em tubos estéreis contendo heparina. As amostras de sangue materno foram colhidas 24 horas antes do parto cesáreo porque a infusão contínua de AZT durante a cirurgia altera as propriedades físico-químicas das amostras, o que inviabiliza a purificação de células mononucleares periféricas (PBMC) pelos métodos empregados em nosso laboratório. O mesmo procedimento foi conduzido para obtenção de sangue periférico de mulheres normais com o mesmo tempo de gravidez, porém, HIV-1 negativas.

Para obter PBMC, o sangue total foi processado como descrito em Baseler et al. ${ }^{22}$. Resumidamente, o sangue total foi centrifugado a $1200 \mathrm{rpm}$ por 10 minutos em centrífuga refrigerada a $25^{\circ} \mathrm{C}$. Alíquotas do plasma de cada amostra foram então reservadas para avaliação posterior da carga viral e da presença de citocinas periféricas. O volume total de células e hemácias que ficaram nos tubos contendo heparina foi ressuspenso em solução salina em proporção 1:2 (v/v). Em seguida, $30 \mathrm{~mL}$ dessa amostra diluída foram colocados em tubos estéreis contendo $15 \mathrm{~mL}$ de solução de FicollHypaque $(\mathrm{d}=1.007 \mathrm{~g} / \mathrm{L})$ (Pharmigen) e foram submetidos a centrifugação a $2500 \mathrm{rpm} / 25^{\circ} \mathrm{C}$. Após 25 minutos, os tubos foram removidos e as PBMC recuperadas com uso de pipetas Pasteur estéreis, na interface entre a salina e a solução de Ficoll. As células obtidas foram, em seguida, submetidas a três procedimentos de lavagem com meio de cultura de RPMI 1640 (Sigma Co.).
As PBMC purificadas foram contadas em solução de azul de Trypan a 4\% (v/v) e a concentração de células viáveis foi ajustada para $1,5 \times 10^{6} /$ $\mathrm{mL}$. Em seguida, a suspensão celular foi diluída em meio RPMI completo antes de ser colocada em cultura em atmosfera úmida a $37^{\circ} \mathrm{C} / 7 \% \mathrm{CO}_{2}$. Esse meio completo é composto de meio de cultura RPMI 1640 suplementado com $50 \mathrm{U} / \mathrm{mL}$ de penicilina, $50 \mu \mathrm{g} / \mathrm{mL}$ de estreptomicina, $2 \mathrm{mM}$ de L-glutamina e $10 \mathrm{mM}$ de tampão HEPES. Para enriquecê-lo, adicionamos soro fetal bovino previamente inativado pelo calor $\left(56^{\circ} \mathrm{C} / 45\right.$ minutos) a $10 \%(\mathrm{v} / \mathrm{v})$.

\section{Medida da replicação viral plasmática}

Para obtenção de plasma, $5 \mathrm{~mL}$ de sangue total foram submetidos a centrifugação por $5 \mathrm{mi}$ nutos a $1200 \mathrm{rpm}$. Um mililitro do plasma foi recolhido e submetido à avaliação da carga viral plasmática (CVP). A CVP nas amostras maternas e fetais foi medida por procedimento de amplificação de seqüência de ácido nucléico (NASBA, Organon, Holland), com limite de detecção de 80 cópias de RNA do HIV-1 por mL de plasma. Em alguns experimentos, a avaliação da carga viral em cultura foi avaliada na ausência ou presença de doses saturantes de anticorpos anti-IL-10 (BectonDickinson, CA, USA), na dose final de $10 \mu \mathrm{g} / \mathrm{mL}$. Para tanto, aproximadamente $1,5 \times 10^{6} / \mathrm{mL}$ de PBMC obtidas do sangue periférico de gestantes infectadas pelo HIV-1 ( $\mathrm{n}=10)$ com CVP $<10.000$ cópias de RNA do HIV-1/mL foram mantidas em cultura por 5 dias na presença conjunta de fitohemaglutinina (PHA) $(5 \mu \mathrm{g} / \mathrm{mL})$ mais IL-2 $(20 \mathrm{U} /$ $\mathrm{mL}$ ). Para avaliar a replicação, $100 \mu \mathrm{L}$ do sobrenadante de culturas tratadas ou não com anticorpos anti-IL-10 foram recolhidos e levados para quantificação da carga viral, como descrito na metodologia.

\section{Contagem de linfócitos $\mathrm{T} \mathrm{CD}^{+}$e $\mathrm{T} \mathrm{CDS}^{+}$peri- féricos}

A alíquota reservada de sangue total fresco contendo EDTA foi submetida a imunofenotipagem quantitativa das subpopulações majoritárias de linfócitos T periféricos. Para isto, $50 \mu \mathrm{L}$ do sangue total foram adicionados a tubos contendo combinação de anticorpos anti-CD3 marcados com isotiocianato de fluoresceína (FITC) com anti-CD4 marcados com ficoeritina (PE), e outros $50 \mu \mathrm{L}$ pipetados dentro de tubos contendo anticorpos antiCD3-FITC e anti-CD8-PE. Todos os procedimentos subseqüentes foram conduzidos como indicado pelo fabricante (Becton-Dickinson, CA, USA). A contagem final de linfócitos $\mathrm{T} \mathrm{CD} 3^{+} \mathrm{CD}^{+}{ }^{+} \mathrm{T} \mathrm{CD}^{+} \mathrm{CD}^{+}$ foi realizada por citometria de fluxo e por FACSCOUNT (Becton-Dickinson, CA, USA), e os 
resultados expressos em número de cópias de RNA $\operatorname{viral} / \mathrm{mL}$.

\section{Avaliação primária da resposta proliferativa das PBMC frescas obtidas das amostras}

Aproximadamente $1,5 \times 10^{6} / \mathrm{mL}$ de PBMC obtidas do sangue periférico de mães normais (n $=10)$ ou infectadas pelo HIV-1 $(n=12)$ foram mantidas em cultura por sete dias na presença conjunta de PHA a $5 \mu \mathrm{g} / \mathrm{mL}$ mais IL-2 recombinante humana (Sigma, Co.), a $20 \mathrm{U} / \mathrm{mL}$. As células foram mantidas em placas de 96 poços $(200 \mu \mathrm{L})$ de fundo redondo, e foram acompanhadas diariamente ao microscópio invertido. Para quantificar a proliferação celular em diferentes tempos, a suspensão celular total foi delicadamente homogeneizada com pipeta de $1 \mathrm{~mL}$, e alíquotas de $20 \mu \mathrm{L}$ foram removidas e diluídas 200 vezes em solução de azul de Trypan a 4\% (v/m). Em seguida, a suspensão celular total foi deixada repousar em câmara de Neubauer por 3 minutos para que o corante pudesse marcar as células mortas. No microscópio óptico, com a objetiva de 100, foram contados os números de células viáveis nos quatro quadrantes. A densidade celular total foi inferida como o número médio de células \pm desvio-padrão.

\section{Dosagem de citocinas}

Para quantificar a presença de citocinas definidoras de diferentes fenótipos Th (TNF- $\alpha$, IFN$\gamma$, IL-10 e IL-4), amostras dos plasmas e dos sobrenadantes das culturas policlonalmente ativadas ou não foram recolhidas e submetidas à técnica de ELISA indireto, segundo protocolo fornecido pelo fabricante (Pharmigen). Placas de 96 poços foram devidamente sensibilizadas com anticorpo de captura $(4 \mu \mathrm{g} / \mathrm{mL})$ e incubadas por 18 horas a $4^{\circ} \mathrm{C}$. No dia seguinte, as placas foram lavadas com solução de PBS-Tween a 0,1 \% (solução de lavagem), bloqueadas com SFB a 10\% diluído em solução de $\mathrm{PBS}$ e incubadas a $37^{\circ} \mathrm{C}$. Ao final de duas horas, as placas lavadas, foram incubadas a $4^{\circ} \mathrm{C}$ com as amostras testes, bem como os padrões. Após 18 horas, as placas foram exaustivamente lavadas e tratadas com o anticorpo de detecção a 4 $\mu \mathrm{g} / \mathrm{mL}$, e incubadas por uma hora a $37^{\circ} \mathrm{C}$. Ao final deste tempo, as placas foram novamente lavadas e tratadas com estreptoavidina-fosfatase alcalina. Passadas 18 horas a $4^{\circ} \mathrm{C}$, o conteúdo de cada poço na placa foi substituído pelo substrato (PNPP). O produto final da hidrólise pela fosfatase alcalina é o paranitrofenol (PNP), que possui cor amarela. A leitura foi realizada em leitor automatizado BioRad utilizando filtro de $405 \mathrm{~nm}$ e a concentração correspondente a cada valor da densidade ótica (D.O.) obtido foi determinada pela comparação com curva-padrão, com concentrações variando de 100 a $5000 \mathrm{pg} / \mathrm{mL}$.

\section{Análise estatistica}

Para análise estatística da significância das diferenças entre as médias e os desvios-padrão dos valores obtidos entre os grupos de gestantes normais e infectadas com diferentes cargas virais foi utilizado o teste $t$ pareado de Student. As diferenças foram consideradas como estatisticamente significantes quando $\mathrm{p}<0.05$.

\section{Resultados}

Como podemos observar na Tabela 1, dentre as gestantes infectadas pelo HIV-1 recrutadas a participar de nosso estudo, 03 em 12 tinham CVP detectáveis, isto é, mais de 80 cópias de RNA do HIV $-1 / \mathrm{mL}$. Devido ao reconhecimento tardio do estado de portador do vírus pela equipe médica, a introdução da terapia anti-retroviral foi conduzida em tempos avançados da gestação (34-37 semanas). De todas, apenas uma gestante com CVP detectável não estava sob cobertura terapêutica. Dos filhos, três neonatos tinham CVP detectável e a infecção foi posteriormente confirmada pelo método de PCR do DNA pró-viral (dado não mostrado).

Tabela 1 - Características gerais da população estudada, segundo os valores da carga viral plasmática, de linfócitos T $\mathrm{CD} 4^{+}$e TCD8 ${ }^{+}$e terapia anti-retroviral.

\begin{tabular}{lccccrrr}
\hline Pacientes $^{1}$ & Idade & $\begin{array}{c}\text { Tempo } \\
\text { gestacional }\end{array}$ & ARV $^{3}$ & CVP $^{4}$ & T CD4 $^{+5}$ & T CD8 $^{+}$ \\
\hline P01F01 & 27 & 36 & AZT & $330<80$ & 8313.220 & 8731.730 \\
P02F02 & 24 & 36 & AZT & $<80<80$ & 6552.830 & 1.0201 .066 \\
P03F03 & 27 & 37 & AZT & 9.200300 .000 & 5081.506 & 1.569971 \\
P04F04 & 32 & 36 & - & $<80<80$ & 1.2523 .030 & 4912.116 \\
P05F05 & 26 & 36 & AZT/ NVP & $<80<80$ & 9972.785 & 999956 \\
P06F06 & 34 & 35 & - & 160.00014 .000 & 4553.337 & 8761.879 \\
P07F07 & 28 & 36 & AZT/NVP & $<80<80$ & 7802.810 & 996937 \\
P08F08 & 21 & 35 & AZT/NVP & $<80<80$ & 1.1052 .615 & 1.2331 .860 \\
P09F09 & 37 & 34 & AZT & 40.00010 .500 & 5131.750 & 1081945 \\
P10F10 & 35 & 35 & - & $<80<80$ & 8752.351 & 9961.052 \\
P11F11 & 28 & 36 & - & $<80<80$ & 1.3503 .156 & 9961.311 \\
P12F12 & 28 & 36 & AZT & $7.500<80$ & 7133.410 & 9962.105 \\
\hline
\end{tabular}

${ }^{1} \mathrm{P}=$ mãe; $\mathrm{F}=$ filho; ${ }^{2}$ tempo em semanas em que foi introduzida a terapia anti-retroviral; ${ }^{3} \mathrm{ARV}=$ terapia anti-retroviral; ${ }^{4} \mathrm{CVP}=$ carga viral plasmática em número de cópias de RNA do HIV-1/mL; ${ }^{5}$ Os valores de células T CD4 ${ }^{+}$e T CD8 ${ }^{+}$periféricas são fornecidos por mililitro de sangue. 
Quando a resposta linfoproliferativa (Figura 1) induzida por ativadores policlonais (PHA + IL-2) foi avaliada, observamos que, apesar de a cinética da linfoproliferação ter sido similar, o nivel de expansão policlonal foi maior nas culturas de células obtidas de mulheres grávidas saudáveis do que de pacientes grávidas portadoras do $\mathrm{HIV}-1^{+} \mathrm{com}$ CVP $<10.000$ cópias/mL $[4,2 \pm 0,37$ vs 2,4 $\pm 0,56$, $\left(\mathrm{x} 10^{6}\right)$ células $/ \mathrm{mL}$, respectivamente $\left.\mathrm{p}<0,005\right]$ (Figura 1A). Em ambas as amostras, o pico de proliferação celular foi observado entre 5 e 7 dias de cultura. Nas culturas de células ativadas obtidas de gestantes com elevados niveis de CVP (P06 e P09), o pico de linfoproliferação ocorreu entre 24-48 horas, seguido de perda celular progressiva (Figura 1B). Esses resultados sugerem que amostras de PBMC de mulheres grávidas infectadas pelo HIV1 têm padrões desregulados de linfoproliferação como resposta a ativadores policlonais in vitro.
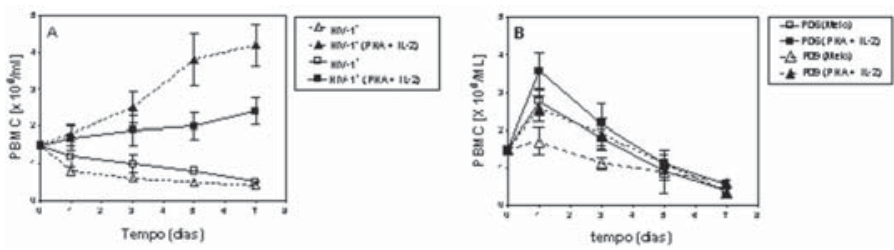

Figura 1 - Avaliação da resposta proliferativa de linfócitos T de gestantes infectadas pelo HIV-1.

Para avaliar a proliferação, $1,5 \times 10^{6} / \mathrm{mL}$ de células mononucleares do sangue periférico (PBMC), obtidas de gestantes HIV-1 negativas (HIV-1') $(n=10)$ ou infectadas $\left(\mathrm{HIV}-1^{+}\right)$ $(n=12)$, foram cultivadas na presença de ativadores policlonais de células $T$ humanas. Em A) temos a proliferação de células T obtidas de mulheres com carga viral plasmática $<10.000$ cópias de RNA/mL, ao passo que em B) temos a atividade mitogênica em cultura de células obtidas de gestantes (P06 e P09) com elevada carga viral ( $<40.000$ cópias de RNA $/ \mathrm{mL}$ ). Os estímulos foram fito-hemaglutinina (PHA, $5 \mu \mathrm{g} / \mathrm{mL}$ ) mais interleucina 2 recombinante (-rlL-2, $20 \mathrm{U} / \mathrm{mL})$. Os valores representam a média \pm desvio padrão.

Além da proliferação, a produção de determinados padrões de citocinas foi pesquisada em nossas amostras. A princípio avaliamos o padrão periférico de citocina produzido pelos indivíduos de nosso estudo. Como pode ser observado na Tabela 2, tanto em mulheres grávidas normais quanto portadoras do HIV-1 com CVP $<10.000$ cópias de $\mathrm{RNA} / \mathrm{mL}$, os niveis de IL-10 foram elevados $(1.015 \pm 455 \mathrm{pg} / \mathrm{mL})$. A produção de IL-4, no entanto, foi inconsistente e não significativamente diferente entre os dois grupos $(p=0,066)$. Produção baixa de IL-10 (251 $\pm 115 \mathrm{pg} / \mathrm{mL})$ e níveis elevados de TNF- $\alpha(565 \pm 105 \mathrm{pg} / \mathrm{mL})$ foram observados no sangue periférico de gestantes com CVP $\geq 40.000$ cópias de RNA/mL (P06 e P09). Esses resultados sugerem padrão desregulado na produção de citocinas no sangue periférico de mulheres grávidas com intensa replicação viral. Padrão similar no perfil de citocinas foi produzido por culturas de células policlonalmente ativadas. Como demonstrado na Figura 2, a produção de IL-10 foi detectada no sobrenadante de culturas de células obtidas de gestantes normais ou infectadas pelo HIV-1 com CVP $<10.000$ cópias de RNA/mL $(9.790 \pm 3.224 \mathrm{pg} / \mathrm{mL})$. Esse balanço é totalmente rompido em gestantes portadoras do HIV-1 com níveis elevados de CVP (P06 e P09).

Tabela 2 - Dosagem de citocinas no sangue periférico de gestantes infectadas pelo HIV-1.

\begin{tabular}{lcccc}
\hline Pacientes & IL-10 & IL-4 $(\mathrm{pg} / \mathrm{mL})^{*}$ & TNF $-\alpha$ & IFN- $\boldsymbol{\gamma}$ \\
\hline HIV-1 negativas $(\mathrm{n}=10)$ & $960 \pm 255$ & $191 \pm 56$ & $<100$ & $<100$ \\
HIV-1 positivas & & & & \\
CVP $<80 / n=7$ & $1015 \pm 455$ & $207 \pm 195$ & $<100$ & $<100$ \\
CVP $\leq 10.000 / n=3$ & $487 \pm 78$ & $156 \pm 26$ & $187 \pm 50$ & $134 \pm 23$ \\
CVP $\geq 40.000 / n=2$ & $251 \pm 115$ & $206 \pm 45$ & $565 \pm 105$ & $201 \pm 98$
\end{tabular}

HIV-1 negativas = gestantes não infectadas pelo HIV-1; HIV-1 positivas = gestantes infectadas pelo HIV-1; CVP = carga viral plasmática (número de cópias de RNA viral/mL). As citocinas dosadas foram as interleucinas 4 e 10 (IL-4 e IL-10), interferon- $\gamma$ e fator $\alpha$ de necrose tumoral. Os valores representam a média \pm desvio padrão.

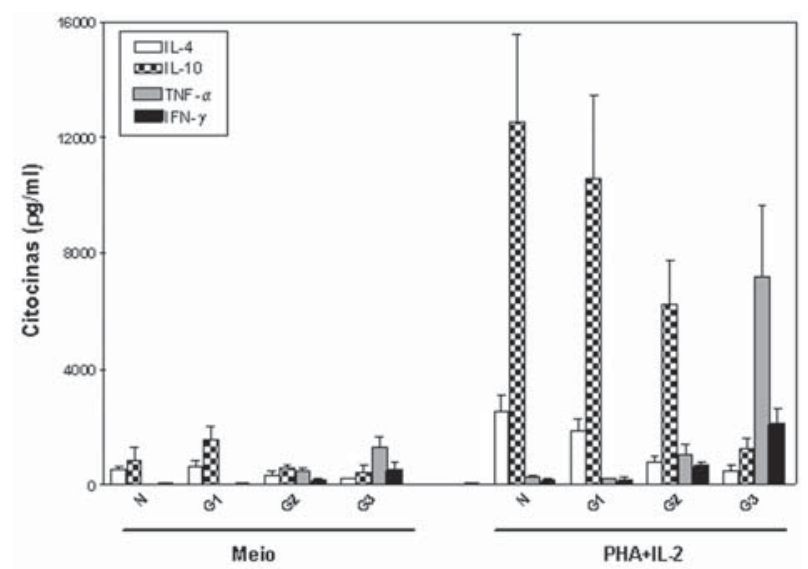

Figura 2 - Produção de citocinas por linfócitos T ativados de gestantes portadoras do HIV-1. Aproximadamente $1,5 \times 10^{6} \mathrm{PBMC} / \mathrm{mL}$ obtidas do sangue periférico de 10 gestantes HIV-1 negativas ( $\mathbf{N}$ ) e de mães infectadas (G), foram cultivadas sem ou com fitohemaglutinina (PHA, $5 \mu \mathrm{g} / \mathrm{mL}$ ) mais interleucina 2 recombinante $(\mathrm{rlL}-2,20 \mathrm{U} / \mathrm{mL})$. Os grupos G1, G2 e G3 representam mulheres infectadas pelo HIV-1 com CVP $<80(n=7)$, $\leq 10.000$ ( $n=3)$ e $\geq 40.000$ ( $n=2)$ cópias de RNA de HIV-1/mL de plasma, respectivamente. Foram dosadas as citocinas interleucinas 4 e 10 (IL-4 e IL-10), o interferon- $\gamma$ (IFN- $\gamma$ ) e o fator $\alpha$ de necrose tumoral (TNF- $\alpha$ ). Os valores representam a média \pm desvio padrão.

O papel da IL-10 endógena na replicação viral foi avaliado a partir do bloqueio funcional desta citocina em culturas de células obtidas das gestantes infectadas pelo HIV-1. Como demonstrado na Figura 3, a adição de anticorpos monoclonais anti-IL-10 aumentou a CVP em todas as culturas de células T ativadas (PHA + IL-2), obtidas de mães que mantinham CVP $<10.000$ cópias de RNA/mL. 


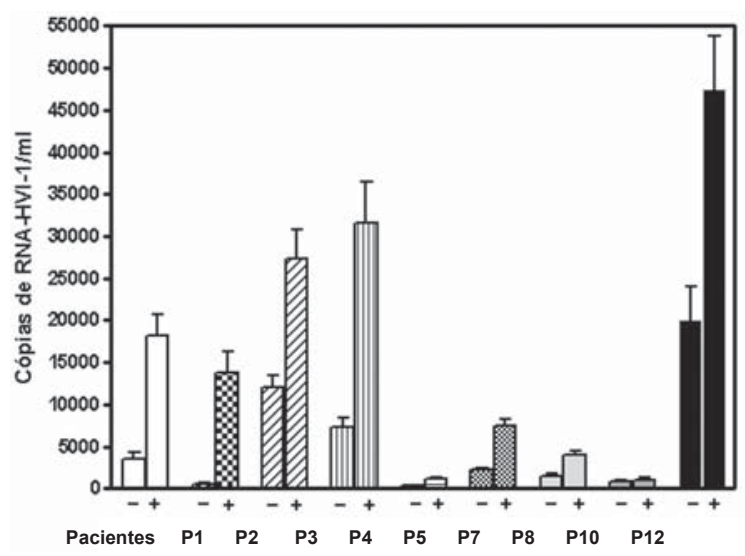

Figura 3 - Papel da IL-10 na replicação do HIV-1 em culturas de linfócitos humanos. Aproximadamente $1,5 \times 10^{6} / \mathrm{mL}$ de células mononucleares do sangue periférico (PBMC) obtidas do sangue periférico de gestantes infectadas pelo HIV-1 $(n=10)$ com CVP $<10.000$ cópias de RNA do HIV-1/mL foram mantidas em cultura por cinco dias na presença conjunta de fito-hemaglutinina (PHA, $5 \mu \mathrm{g} / \mathrm{mL}$ ) mais interleucina 2 recombinante (IL-2, $20 \mathrm{U} / \mathrm{mL}$ ). Em alguns poços foram adicionadas (+) doses saturantes de anticorpo antiIL-10 (10 $\mu \mathrm{g} / \mathrm{mL})$ no início da cultura. Como controle, a replicação viral foi avaliada nos sobrenadantes das culturas mantidas sob as mesmas condições mas sem anti-lL-10 (-).Os resultados são expressos como média \pm DP de experimentos em triplicatas.

\section{Discussão}

A gestação é um estado de tolerância imunológica ao feto. Portanto, o sucesso da gestação se baseia na indução de uma rede de citocinas produzida tanto pela placenta quanto pelos linfócitos $\mathrm{T}$ reguladores maternos. A manutenção desse estado de não responsividade aos antígenos fetais é temporária e é mantida por mudanças hormonais, particularmente pela produção de progesterona. Alguns trabalhos sugerem que estes hormônios induzem linfócitos $\mathrm{T} \mathrm{CD}^{+}$e T CD8 ${ }^{+}$ maternos a se diferenciarem em células reguladoras que secretam citocinas antiinflamatórias, tais como IL-10 e o TGF- $\beta^{2-4}$. A infecção pelo HIV1 , por outro lado, induz um conjunto de distúrbios imunológicos no homem que é medido em grande parte pela produção crônica de citocinas pró-inflamatórias, tais como TNF- $\alpha$ e IFN- $\gamma^{18}$.

Muitos dos distúrbios imunes em pacientes infectados pelo HIV decorrem da produção elevada de citocinas pró-inflamatórias. Um desses eventos envolve anormalidades proliferativas como resposta a antígenos relacionados ou não ao próprio virus ${ }^{17,19}$. Em nosso estudo, a capacidade de proliferação dos linfócitos T obtidos de gestantes saudáveis foi superior quando comparada às culturas de células de gestantes infectadas pelo HIV-1. Uma maior desregulação foi observada em culturas de células obtidas de mulheres com elevado nível de CVP. Nestas últimas amostras, além de a resposta linfoproliferativa máxima ter sido detectada já nas primeiras 24 horas de cultura, este evento foi seguido de perda celular progressiva. Como a infecção pelo HIV-1 induz apoptose em linfócitos T cronicamente ativados ${ }^{17}$, nosso grupo acredita que a elevada produção de citocinas pró-inflamatórias, como o TNF- $\alpha$ detectado em pacientes com elevadas CVPs, esteja envolvida na morte celular induzida por ativação.

No contexto da infecção pelo HIV, o perfil de citocinas secretado pelos linfócitos $\mathrm{T}$ maternos pode facilitar a replicação viral. Para entender melhor a interação entre as redes de citocinas nas gestantes infectadas pelo HIV-1, optamos por usar ativadores de linfócitos $\mathrm{T}$ que não induzissem padrões restritos de citocinas, como PHA e IL-2 recombinante humana. Nesse sentido, nossos dados revelaram que a produção elevada de IL-10 deve ser originária de linfócitos T reguladores do tipo 1 ( $\operatorname{Tr}-1)$ em gestantes normais ou infectadas pelo HIV-1 com CVP reduzida. Estes resultados estão de acordo com outros dados publicados na literatura, que revelam tendência materna de desenvolver um padrão de células reguladoras (Tr-1) em resposta a diferentes estimulos antigênicos ${ }^{3,4,6,7,13,15}$. Quando comparadas às pacientes com CVP indetectáveis ou reduzidas, gestantes com elevado nivel de replicação viral, no entanto, apresentaram produção de TNF- $\alpha$ expressivamente superior à de IL-10. Portanto, na infecção pelo HIV a manutenção de um padrão celular Th-1 no sangue materno deve alterar o delicado equilíbrio de citocinas antiinflamatórias produzidas pelas gestantes em condições normais.

A presença de citocinas periféricas, tal como TNF- $\alpha$, deve facilitar a replicação viral nos reservatórios imunes maternos. O controle da CVP passa a ser fundamental, pois dentre os múltiplos fatores imunogenéticos maternos que podem determinar a taxa de risco de infecção neonatal, o inóculo viral ao qual o filho é exposto é de longe o principal determinante de transmissão vertical. Dados recentes obtidos a partir de coorte de 297 mulheres acompanhadas há cinco anos no Hospital dos Servidores do Estado do Rio de Janeiro demonstram que o risco de transmissão vertical do HIV-1 é amplamente reduzido em mulheres que aderiram mais precocemente à terapia antiretroviral indicada ${ }^{23}$. A replicação viral persistente pode comprometer o desenvolvimento normal do feto, podendo acarretar o nascimento de pequenos para a idade gestacional, partos prematuros e mesmo abortos espontâneos ${ }^{24,25}$. Todos esses fenômenos parecem estar associados à produção sustentada de citocinas pró-inflamatórias na interface materno-fetal ${ }^{26,27}$. Trabalho recente ${ }^{28}$ revelou que rejeição ao feto por gatas grávidas 
infectadas com o vírus da imunodeficiência felina, que possui muitas similaridades biológicas e clínicas com o HIV em humanos, foi um fenômeno imunológico induzido pela expressão de citocinas Th1 na interface decídua-placenta. Apesar de nossa amostra ter sido pequena, nossos dados revelaram estreita relação entre niveis elevados de citocinas Th1 com transmissão vertical do HIV-1.

Um achado interessante do nosso estudo foi que a neutralização da IL-10 endógena com anticorpos monoclonais aumentou a replicação viral em cultura de linfócitos T maternos ativados por PHA mais IL-2 recombinante. Enquanto a produção de IFN- $\gamma$ e TNF- $\alpha$ pode facilitar tanto a infecção produtiva de células-alvo saudáveis quanto amplificar a replicação em células contendo o DNA pró-viral ${ }^{18-21}$, a IL-10 e/ou TGF- $\beta$ mais IL-13 inibem a replicação viral em sistemas de infecção aguda $^{28-30}$. A IL-10 e o TGF- $\beta$, por induzirem um ambiente antiinflamatório, podem colaborar na proteção do feto na cavidade uterina por bloquear a atividade lítica mediada pelas células uterinas assassinas, tais como NK e T CD8. No momento nosso grupo vem analisando o envolvimento do TFG- $\beta$ na capacidade replicativa viral, bem como na identificação do subtipo de linfócitos T responsável pela produção dessas citocinas.

Em resumo, nossos resultados sugerem que a produção de IL-10 exerce uma pressão negativa na replicação do HIV-1, o que pode, indiretamente, reduzir o risco de transmissão vertical da infecção. Acreditando nessa inter-relação, nosso grupo atualmente continua coletando amostras de sangue periférico das gestantes visando obter a comparação concreta dessa hipótese.

\section{Agradecimentos}

Agradecemos a Kátia Tavares, Silvana Pereira e a Fátima Napoleão pelo apoio técnico fornecido ao trabalho e ao Dr. Regis Mariano de Andrade pelas contribuições na revisão deste manuscrito.

\section{Referências}

1. Hatthachote P, Gillespie JI. Complex interactions between sex steroids and cytokines in the human pregnant myometrium: evidence for an autocrine signaling system at term. Endocrinology. 1999;140(6):2533-40.
2. Lim KJ, Odukoya OA, Aijan RA, Li TC, Weetman AP, Cooke ID. The role of T-helper cytokines in human reproduction. Fertil Steril. 2000;73(1):13642.

3. Saito S, Sasaki Y, Sakai M. CD4(+)CD25high regulatory $\mathrm{T}$ cells in human pregnancy. J Reprod Immunol. 2005;65(2):111-20.

4. Zenclussen AC, Gerlof K, Zenclussen ML, Sollwedel A, Bertoja AZ, Ritter $\mathrm{T}$, et al. Abnormal T-cell reactivity against paternal antigens in spontaneous abortion: adoptive transfer of pregnancy-induced CD4+CD25+T regulatory cells prevents fetal rejection in a murine abortion model. Am J Pathol. 2005;166(3):811-22.

5. Abbas BK, Lichtman A. Imunologia celular e molecular. 5 ${ }^{\mathrm{a}}$ ed. Amsterdam: Elsevier; 2005. p. 327.

6. Polanczyk MJ, Carson BD, Subramanian S, Afentoulis M, Vandenbark AA, Ziegler SF, et al. Cutting edge: estrogen drives expansion of the CD4+CD25+regulatory $\mathrm{T}$ cell compartment. J Immunol. 2004;173(4):2227-30.

7. Marzi M, Vigano A, Trabattoni D, Villa ML, Salvaggio A, Clerici E, et al. Characterization of type 1 and type 2 cytokine production profile in physiologic and pathologic human placenta. Clin Exp Immunol. 1996;106(1):127-33.

8. Hill JA 3rd, Choi BC. Immunodystrophism: evidence for a novel alloimmune hypothesis for recurrent pregnancy loss involving Th1-type immunity to trophoblasts. Semin Reprod Med. 2000;18(4):4015 .

9. Dent LA. For better or worse: common determinants influencing health and disease in parasitic infections, asthma and reproductive biology. J Reprod Immunol. 2002;57(1-2):255-72.

10. Ruth V, Hallman M, Laatikainen T. Corticotropin-releasing hormone and cortisol in cord plasma in relation to gestational age, labor and fetal distress. Am J Perinatol. 1993;10(2):115-8.

11. Miller L, Hunt JS. Regulation of TNF- $\alpha$ production in activated mouse macrophages by progesterone. J Immunol. 1998;160(10):5098-104.

12.Blanco-Quiros A, Arranz E, Solis G, Villar A, Ramos A, Coto D. Cord blood interleukin-10 levels are increased in preterms newborns. Eur $\mathrm{J}$ Pediatr. 2000;159(6):420-3.

13. Roth I, Corry DB, Locksley RM, Abrams JS, Litton MJ, Fisher SJ. Human placental cytotrophoblasts produce the immunosuppressive cytokine interleukin 10. J Exp Med. 1996;184(2):539-48.

14. Piccini MP, Giudizi MG, Biagiotti R, Beloni L, Giannarini L, Sampognaro S, et al. Progesterone favors the development of human $\mathrm{T}$ helper cells producing Th2-type cytockines and promotes both IL-4 production and membane CD30 expression in 
established Th1 cells clones. J Immunol. 1995;155(1):128-33.

15.Daya S, Rosenthal KL, Clark DA. Immunosuppressor factor(s) produced by deciduaassociated suppressor cells: a proposed mechanism for fetal allograft survival. Am J Obstet Gynecol. 1987;156(2):344-50.

16. Ministério da Saúde. Secretaria de Vigilância em Saúde. Programa Nacional de DST/AIDS. Recomendação para a profilaxia da transmissão vertical do HIV e terapia anti-retroviral em gestantes. Brasília (DF); 2004.

17. Lieberman J, Shankar P, Manjunath N, Andersson J. Dressed to kill? A review of why antiviral CD8 T lymphocytes fail to prevent progressive immunodeficiency in HIV-1 infection. Blood. 2001;98(6):1667-77.

18. Jassoy C, Harrer T, Rosenthal T, Navia BA, Worth $\mathrm{J}$, Johnson RP, et al. Human immunodeficiency virus type 1 -specific cytotoxic T lymphocytes release gamma interferon, tumor necrosis factor alpha (TNFalpha), and TNF-beta when they encounter their target antigens. J Virol. 1993;67(5):2844-52.

19. Bentwich Z, Kalinkovich A, Weisman Z. Immune activation is a dominant factor in the pathogenesis of Africa AIDS. Immunol Today. 1995;16(4):187-91.

20.Staprans S, Hamilton BL, Follansbee SE, Elbeik T, Barbosa P, Grant RM, et al. Activation of virus replication after vaccination of HIV-1 infected individuals. J Exp Med. 1995;182(6):1727-37.

21. Goletti D, Weissman D, Jackson RW, Graham NM, Vlahov D, Klein RS, et al. Effect of Mycobacterium tuberculosis on HIV replication. Role of immune activation. J Immunol. 1996;157(3):1271-8.

22. Baseler MW, Stevens RA, Lambert LA, Metcalf AA. Immunologic evaluation of patients with human immunodeficiency infection. In: Rose NR, Macario EC, Folds J, Lane C, Nakamura RM, editors. Manual of clinical laboratory immunology. Washington, (DC): ASM; 1997. P. 764-72.
23.João EC, Cruz ML, Menezes JA, Matos HJ, Calveti GA, d'Ippolito MM, et al. Vertical transmission of HIV in Rio de Janeiro, Brazil. AIDS. 2003;17(12):1853-5.

24. D'Ubaldo C, Pezzotti P, Rezza G, Branca M, Ippolito G. Association between HIV-1 infection and miscarriage: a retrospective study. DIANAIDS Collaborative Study Group. Diagnosi Iniziale Anomalie Neoplastiche AIDS. AIDS. 1998;12(9):1087-93.

25. Kumar RM, Uduman SA, Khurranna AK. Impact of maternal HIV-1 infection on perinatal outcome. Int J Gynaecol Obstet. 1995;49(2):137-43.

26. Moussa M, Roques P, Fievet N, Menu E, MaldonadoEstreada JG, Brunerie J, et al. Placental cytokine and chemokine production in HIV-1-infected women: trophoblast cells show a different pattern compared to cells from HIV-negative women. Clin Exp Immunol. 2001;125(3):455-64.

27. Lee BN, Hammill H, Popek EJ, Cron S, Kozinetz C, Paul M, et al. Production of interferons and betachemokines by placental trophoblasts of HIV-1infected women. Infect Dis Obstet Gynecol. 2001;9(2):95-104.

28. Weaver CC, Burgess SC, Nelson PD, Wilkinson M, Ryan PL, Nail CA, et al. Placental immunopathology and pregnancy failure in the FIV-infected cat. Placenta. 2005;26(2-3):138-47.

29. Poli G, Kinter AL, Justement JS, Bressler P, Kehrl $\mathrm{JH}$, Fauci AS. Transforming growth factor beta suppresses human immunodeficiency virus expression and replication in infected cells of the monocyte/macrophage lineage. J Exp Med. 1991;173(3):589-97.

30. Clereci M, Wynn TA, Berzofsky JA, Blatt SP, Hendrix $\mathrm{CW}$, Sher A, et al. Role of IL-10 in T helper cell dysfunction in asymptomatic individuals infected with human immunodeficiency virus. J Clin Invest. 1994;93(2):768-75. 